Rev. Bras. Saúde Prod. Anim., Salvador, v.16, n.1, p.161-169jan./mar., $2015 \quad$ http://www.rbspa.ufba.br ISSN 15199940

http://dx.doi.org/10.1590/S1519-99402015000100017

\title{
Incidência de ruminite e abscesso hepático em bovinos jovens confinados alimentados com dietas contendo aditivos alimentares
}

\author{
Incidence of ruminite and liver abscess of feedlot bullocks fed high concentrate diets \\ containing feed additives
}

\author{
BARDUCCI, Robson Sfaciotti ${ }^{1 *}$; SARTI, Luís Marcelo Nave ${ }^{1}$; MILLEN, Danilo \\ Domingues $^{3}$; PACHECO, Rodrigo Dias Lauritano ${ }^{1}$; MARTINS, Cyntia Ludovico ${ }^{2}$; \\ ARRIGONI, Mário De Beni ${ }^{1}$
}

\author{
${ }^{1}$ Universidade Estadual Paulista, Faculdade de Medicina Veterinária e Zootecnia, Departamento de \\ Melhoramento e Nutrição Animal, Botucatu, São Paulo, Brasil. \\ ${ }^{2}$ Universidade Estadual Paulista, Faculdade de Medicina Veterinária e Zootecnia, Departamento de Produção \\ Animal, Botucatu, São Paulo, Brasil. \\ ${ }^{3}$ Universidade Estadual Paulista, Faculdade de Medicina Veterinária e Zootecnia, Dracena, São Paulo, Brasil. \\ *Endereço para correspondência: robsonbarducci@yahoo.com.br
}

\section{RESUMO}

O objetivo deste estudo foi avaliar o efeito da inclusão do preparado de anticorpos policlonais (PAP) e/ou de monensina sódica (MON) na morfologia das papilas ruminais, incidência de ruminites (IR) e abscessos hepáticos (AH) em bovinos jovens confinados. Foram utilizados 72 novilhos da raça Brangus, não castrados, com peso vivo inicial de $261,04 \pm 34,73 \mathrm{~kg}$, em 24 baias (3 animais/baia) com 6 repetições por tratamento. $\mathrm{O}$ delineamento experimental foi inteiramente casualizado em arranjo fatorial $2 \times 2$, sendo os fatores a adição ou não de MON e PAP. Após o abate foram realizadas as avaliações. No fígado tanto o percentual de $\mathrm{AH}$ quanto a severidade foram menores $(\mathrm{P}<0,01)$ nos animais que receberam PAP em relação aos que não receberam. A inclusão de MON foi apenas eficiente em reduzir $(\mathrm{P}<0,01)$ a severidade dos $\mathrm{AH}$ em relação ao tratamento sem o aditivo. Não houve efeito dos aditivos sobre o IR. O tratamento com MON resultou em maior $(\mathrm{P}=0,07)$ superfície de absorção/ $\mathrm{cm}^{2}$ de parede de rúmen e maior $(\mathrm{P}=0,10)$ área papilar em relação ao tratamento sem este aditivo. Número de papilas $/ \mathrm{cm}^{2}$ de parede e área média das papilas não apresentaram diferenças entre tratamentos. O uso de PAP foi eficiente na redução de $\mathrm{AH}$ bem como a severidade, porém não foi capaz de melhorar a forma e a estrutura das papilas ruminais, como o observado com o uso de MON.

Palavras-chave: Fusobacteriumnecrophorum, imunização, ionóforo, papilas

\section{SUMMARY}

The aim of this study was to evaluate the effects of polyclonal antibodies preparation (PAP) and/or monensin (MON) on the morphology of the rumen papillae, incidence of ruminate (IR) and liver abscess in feedlot bullocks. Seventy-two bullocks Brangus $(261.04 \pm 34.73 \mathrm{~kg})$ were housed in 24 pens (3 bullocks/pen) with6 replications per treatment. The experimental design was completely randomized $2 \times 2$ factorial, the factors werethe inclusion or not of MON and PAP.After slaughter, the evaluations were performed. For the livers, both the percentage of abscesses and the severity of them were lower $(P<0.01)$ in animals fed diets with PAP than those fed MON. The inclusion of MON in the diet was only effective in reducing $(P<0.01)$ the severity of the abscesses in relation to treatment without this additive. There was no effect $(P>0.05)$ of additives on the IR. The treatment with MON had higher $(P=0.07)$ surface absorption $/ \mathrm{cm}^{2}$ wall of the rumen and greater $(P=0.10)$ papillary area compared to treatment without this additive. Number of papillae/ $\mathrm{cm}^{2}$ wall and average area of the papillae showed no difference among treatments. The use of PAP was effective in reducing $\mathrm{HA}$ as well as the severity the same, but was not able to improve the shape and structure of the ruminal papillae, as observed with the use of MON.

Keywords: Fusobacteriumnecrophorum, immunization, ionophore, papillae 


\section{INTRODUÇÃO}

O processo digestivo dos alimentos no rúmen se processa principalmente pela ação dos microrganismos para utilização de substratos para sua sobrevivência e multiplicação. A fermentação microbiana e a produção de ácidos graxos de cadeia curta (AGCC) no rúmen são eventos nutricionalmente importantes, no qual grande parte da exigência energética dos ruminantes pode ser atendida. Para alcançar desempenho satisfatório dentro do confinamento, são importantes altas taxas de produção e absorção desses ácidos. Entretanto, a ingestão de dietas ricas em carboidratos rapidamente fermentáveis pode resultar em acúmulo excessivo de AGCC no fluido ruminal, desencadeando quadros de acidose (BERNARDES et al., 2007), com efeitos inibitórios da absorção.

A acidose ruminal crônica está associada a muitas doenças de bovinos confinados que podem ter impacto significativo no desempenho e saúde animal, podendo afetar a motilidade ruminal, a ingestão e a morfologia da parede ruminal (NAGARAJA \& TITGEMEYER, 2007a; COSTA et al., 2008), além de propiciar o aparecimento de ruminites e posteriormente de abscessos no fígado. O termo "complexo ruminite abscesso hepático" vem sendo utilizado devido à alta correlação entre os abscessos hepáticos e as lesões ruminais.

Dentro do sistema de confinamento, a manipulação dietética através de uso de aditivos torna-se ferramenta indispensável na prevenção de doenças e distúrbios alimentares, podendo também contribuir com estímulo da capacidade de remoção de AGCC pela parede do rúmen através de mudanças na morfologia papilar, propiciando alta absorção de energia sem induzir acúmulo excessivo de AGCC no fluido ruminal (COSTA et al., 2008).

Uma nova tecnologia como forma de modificar a fermentação ruminal, está em fase de desenvolvimento, chamados anticorpos policlonais, os quais são basicamente anticorpos contra populações específicas de bactérias ruminais relacionadas a distúrbios metabólicos, como a acidose, e doenças como abscessos de fígado, podendo ser uma nova alternativa em substituição aos aditivos ionóforos (BERGHMAN \& WAGHELA, 2004; NEWBOLD, 2007; BLANCH et al., 2009; MARINO et al., 2011).

Desta forma, conduziu-se este trabalho com o objetivo de avaliar o efeito dos anticorpos policlonais contra as bactérias ruminais Streptococcus bovis, Fusobacterium necrophorum, Lactobacillus e endotoxina na morfologia das papilas ruminais, incidência de ruminite e abscesso hepático em bovinos jovens confinados com elevada proporção de concentrado na dieta.

\section{MATERIAL E MÉTODOS}

Este estudo foi conduzido conforme normas do comitê de ética (protocolo $\mathrm{n}^{\mathrm{o}}$ 77/2008 - CEEA) da Faculdade de Medicina Veterinária e Zootecnia - FMVZ, UNESP/Botucatu. O experimento foi realizado no período de setembro de 2008 a janeiro de 2009.

Foram utilizadas as instalações do confinamento na Fazenda Experimental Lageado da Faculdade de Medicina Veterinária e Zootecnia, UNESP/Botucatu, onde foram alocados 72 novilhos Brangus, não castrados, desmamados aos nove meses de idade, com peso vivo médio inicial de 261,04 $\pm 34,73 \mathrm{~kg}$, distribuídos aleatoriamente em 24 baias (3 animais/baia).

O delineamento experimental foi inteiramente casualizado em arranjo fatorial $2 \times 2$, sendo os fatores a adição ou não de monensina sódica (MON) e a adição ou não de preparado de anticorpos policlonais (PAP) (contra as bactérias ruminais Streptococcusbovis, Fusobacteriumnecropho rum, Lactobacilluse endotoxina). Foram utilizados quatro tratamentos: sem aditivo (controle); PAP; MON e mistura de PAP + MON (MIX), sendo 6 repetições (baias) por tratamento. 
Foram utilizadas três dietas: adaptação, crescimento e terminação (Tabela 1). A adaptação foi feita através de aumento gradual do nível de concentrado, distribuídas em três dietas, onde cada uma permaneceu por sete dias, até completar 21 dias de adaptação; detalhes na Tabela 1. Os animais receberam essas dietas duas vezes ao dia com água à vontade em bebedouros automáticos. Da quantidade diária total oferecida, $40 \%$ foram dados no período da manhã (08:00h) e $60 \%$ no período da tarde (15:00h). As dietas diferiram apenas quanto aos aditivos alimentares utilizados: controle (sem aditivo), MON (30mg/kg de MS), PAP $(450 \mathrm{mg} / \mathrm{kg}$ de MS) ou MIX $(30 \mathrm{mg}+450 \mathrm{mg} / \mathrm{kg}$ de MS, para MON e PAP, respectivamente), estes na forma de pó e pré-misturados ao suplemento mineral. $\mathrm{O}$ sal mineral pronto e atendendo as exigências dos animais, composto pelos tratamentos, era adicionado à dieta juntamente com o fornecimento da ração diária através do sistema de top dress, onde era pulverizado sobre a ração e misturado com o auxílio de pás, de forma uniforme, para garantir a total mistura do sal minetal+aditivos à dieta.

Tabela 1. Composição e conteúdo nutricional das dietas oferecidas aos animais

\begin{tabular}{|c|c|c|c|c|c|}
\hline Dietas & Adap $^{1} . \mathrm{I}$ & Adap. II & Adap. III & Crescimento & Terminação \\
\hline Período (dias) & 7 & 7 & 7 & 66 & 42 \\
\hline Níveis de concentrado & $57 \%$ & $63 \%$ & $68 \%$ & $73 \%$ & $82 \%$ \\
\hline \multicolumn{6}{|l|}{ Ingredientes (\%MS) } \\
\hline Bagaço de cana & 26,94 & 23,48 & 20,71 & 21,77 & 13,62 \\
\hline Feno & 15,37 & 14,02 & 12,58 & 5,12 & 4,54 \\
\hline SGUM $^{2}$ & 23,14 & 27,74 & 32,21 & 36,20 & 47,52 \\
\hline Polpa Cítrica & 12,33 & 12,96 & 13,34 & 15,25 & 19,98 \\
\hline Farelo de Soja & 20,70 & 20,27 & 19,63 & 20,14 & 12,85 \\
\hline $\operatorname{SPMU}(30 \%)^{3}$ & 1,53 & 1,53 & 1,53 & 1,52 & 1,51 \\
\hline \multicolumn{6}{|l|}{ Conteúdo nutricional } \\
\hline $\operatorname{MS}(\%)^{4}$ & 72 & 71 & 69 & 70 & 68 \\
\hline Proteína Bruta (\%) & 15,6 & 15,7 & 15,8 & 16,0 & 13,8 \\
\hline $\operatorname{FDN}(\%)^{5}$ & 37,1 & 33,6 & 30,3 & 25,9 & 19,2 \\
\hline $\operatorname{NDT}(\%)^{6}$ & 71 & 73 & 75 & 76 & 80 \\
\hline $\mathrm{NEg}(\mathrm{Mcal} / \mathrm{kg})^{7^{*}}$ & 1,05 & 1,11 & 1,16 & 1,20 & 1,31 \\
\hline $\mathrm{CNF}^{8^{*}}$ & 41,0 & 45,0 & 48,0 & 52,0 & 61,0 \\
\hline Cálcio (\%) & 0,54 & 0,54 & 0,54 & 0,55 & 0,62 \\
\hline Fósforo (\%) & 0,34 & 0,35 & 0,35 & 0,36 & 0,34 \\
\hline
\end{tabular}

${ }^{\mathrm{I}}$ Dietas de adaptação; ${ }^{2}$ Silagem de grão úmido de milho; ${ }^{3}$ Suplemento Mineral com $30 \%$ de Ureia (continha - Ca 9,1\%; P 4,0\%; Na 12,3\%; S 1,4\%; Mg 0,8\%; Zn 2592 ppm; Mn 1398 ppm; Cu 1032 ppm; I 45,0 ppm;Se 15,0 ppm; Co, 154 ppm e Flúor $400 \mathrm{ppm}) ;{ }^{4}$ Matéria seca; ${ }^{5}$ Fibra em detergente neutro; ${ }^{6}$ Nutrientes digestíveis totais; ${ }^{7}$ Energia liquida para ganho; ${ }^{8}$ Carboidratos Não Fibrosos.

*Segundo equações do CNCPS (2000).

A dieta foi submetida a ajustes de quantidade diariamente, com base na quantidade de sobra nos cochos antes da primeira refeição (08:00h). Para o controle diário de consumo foi utilizada sobra de cocho de aproximadamente $5 \%$.
Os animais foram abatidos após alcançarem o peso de abate de no mínimo 16 arrobas e uma cobertura de gordura de acabamento de no mínimo quatro milímetros para atender as exigências do mercado do frigorífico comercial. 
Para as avaliações das papilas ruminais, logo após o abate, todos os animais tiveram os rumens lavados e examinados. As papilas ruminais foram classificadas conforme a incidência de lesões (índice ruminites - IR) seguindo a metodologia proposta por Bigham \& Mcmanus (1975), baseada numa escala de 0 a 10 pontos.

Para as variáveis morfológicas foram coletados fragmentos de aproximadamente $1 \mathrm{~cm}^{2}$ do saco cranial do rúmen, colocados em frascos contendo solução de tampão fosfato (PBS, $\mathrm{pH} 7,2$ ) e mantidas por um dia refrigeradas até a realização das mensurações. As variáveis avaliadas foram número de papilas por $\mathrm{cm}^{2}$ de parede, área das papilas e da superfície total de absorção por $\mathrm{cm}^{2}$ de parede. $\mathrm{O}$ número de papilas no todo inteiro foi mensurado por três avaliadores e o valor médio determinado para cada animal. A área da superfície absortiva foi mensurada em imagens digitalizadas das papilas e da superfície parietal dos fragmentos coletados através do Programa de análise de imagens UTHSCSA Image Tool, software livre (RESENDE JÚNIOR et al., 2006). Em cada fragmento foi mensurada a área da face parietal e a área de doze papilas seccionadas aleatoriamente na base. A superfície total de absorção foi calculada pela soma da área de epitélio papilar com a área de superfície parietal subtraída da área da base papilar.

Abscessos hepáticos ( $\mathrm{AH})$ foram classificados de acordo com a severidade em escala de 0 a 3 (BRINK et al., 1990), e categorizada como segue: (0) fígados sem abscessos; $(\mathrm{A}-\mathrm{=}$ 1) fígados com um ou dois pequenos abscessos (bem menores que $2,5 \mathrm{~cm}$ de diâmetro) ou cicatrizes de abscessos; $(\mathrm{A}=2)$ fígados com dois a quatro abscessos ativos (pouco menores que $2,5 \mathrm{~cm}$ de diâmetro); $(\mathrm{A}+=3)$ fígados com um ou mais, grandes abscessos (maiores que $2,5 \mathrm{~cm}$ de diâmetro) e porções do diafragma aderido à superfície do fígado. Foi considerada para análise, a porcentagem de animais acometidos por abscessos dentro de cada tratamento, obtendo-se com isso a incidência de $\mathrm{AH}$ propriamente dita.

Os dados foram analisados pelo PROC MIXED do SAS (STATISTICAL ANALYSIS SYSTEMS, 2003), com teste de Tukey para comparação entre médias e resultados considerados significantes a $\mathrm{P}<0,05$. Para valores de $\mathrm{P} \geq 0,05$ a $\mathrm{P} \leq 0,10$ os resultados foram considerados tendência. OIR (dados não paramétricos) foram analisados pelo NPAR1WAY procedimento do SAS (STATISTICAL ANALYSIS SYSTEMS, 2003) e teste de Kruskall-Wallis para comparação entre médias. Os AH foram analisados utilizando-se o PROC FREQ do SAS (STATISTICAL ANALYSIS SYSTEMS, 2003) para testar as diferenças.

\section{RESULTADOSE DISCUSSÃO}

Não foi observado efeito de aditivo sobre a IR, no qual apresentou valores muito baixos, não ultrapassando 0,5 pontos (Tabela 2). Possivelmente, não houve desafio suficiente aos animais do presente estudo, evidenciado com o grupo controle, que apresentou baixos IR. Segundo Pacheco et al. (2012), menor incidência de lesões ruminais foi observada em animais recebendo PAP, quando comparados àqueles que receberam $\mathrm{MON}$, sendo o PAP mais eficientes no controle da acidificação ruminal.

O baixo IR observado pode ser decorrente do manejo alimentar adotado, onde foi utilizado protocolo de adaptação com elevação gradual dos níveis de concentrado da dieta, além do fato da dieta utilizada não ser tão agressiva. Segundo Krause \& Oetzel (2006), maior aparecimento de lesões no rúmen é devido à acidificação ruminal por consequência da produção em excesso de AGCC.

Possivelmente, neste estudo, pode ter ocorrido melhor distribuição na frequência de alimentação dos animais, isto é, menor taxa de ingestão e quantidade de alimento por refeição, evitando o acúmulo de AGCC 
e variação intensa no $\mathrm{pH}$ do rúmen, e consequente aparecimento de lesões na parede ruminal. Em estudo semelhante e utilizando PAP na dieta, Mariani (2010) reportou que os animais que receberam ração com MON apresentaram maior número de refeições/dia e menor tempo de alimentação/refeição que animais recebendo PAP, indicando que, como a ingestão de matéria seca/refeição foi numericamente menor, animais em dietas com MON foram mais vezes ao cocho. No presente estudo não foi avaliado o comportamento alimentar, o que poderia contribuir para inferir de maneira consistente nesta questão.

Tabela 2. Índice de Ruminite e morfologia da parede ruminal de bovinos jovens confinados alimentados com dietas contendo anticorpos policlonais e/ou monensina sódica

\begin{tabular}{|c|c|c|c|c|c|c|c|c|}
\hline \multirow{2}{*}{ Itens } & \multicolumn{2}{|c|}{$\mathrm{MON}^{1}$} & \multicolumn{2}{|c|}{$\mathrm{PAP}^{2}$} & \multicolumn{2}{|c|}{ Probabilidade } & \multirow{2}{*}{$\mathrm{EPM}^{3}$} & \multirow{2}{*}{ Interaçãc } \\
\hline & - & + & - & + & MON & PAP & & \\
\hline Índice de Ruminite (IR) & 0,44 & 0,36 & 0,47 & 0,33 & 0,66 & 0,46 & 0,132 & $\mathrm{NS}^{4}$ \\
\hline Superfície de absorção/ $\mathrm{cm}^{2}$ de parede $\left(\mathrm{cm}^{2}\right)$ & $19,45^{\mathrm{a}}$ & $24,92^{\mathrm{b}}$ & 22,24 & 22,13 & 0,07 & 0,96 & 2,023 & NS \\
\hline Número de papilas $/ \mathrm{cm}^{2}$ de parede & 43,61 & 49,66 & 45,25 & 48,03 & 0,35 & 0,66 & 4,516 & NS \\
\hline Área papilar (\% da superfície de absorção) & $94,30^{\mathrm{a}}$ & $96,07^{\mathrm{b}}$ & 95,09 & 95,28 & 0,10 & 0,86 & 0,759 & NS \\
\hline Área média das papilas $\left(\mathrm{cm}^{2}\right)$ & 0,45 & 0,50 & 0,47 & 0,47 & 0,37 & 0,98 & 0,038 & NS \\
\hline
\end{tabular}

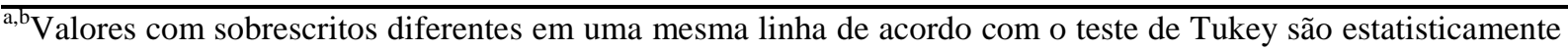
diferentes a $\mathrm{P}<0,05$ e tendência a $\mathrm{P} \geq 0,05$ e $\mathrm{P} \leq 0,10$.

${ }^{1}$ Sem monensina sódica; + com monensina sódica.

${ }^{2} \mathrm{Sem}$ anticorpos policlonais; + com anticorpos policlonais.

${ }^{3}$ Erro padrão médio.

${ }^{4} \mathrm{NS}=$ não significativo $(\mathrm{P}>0,05)$.

Para o número de papilas $/ \mathrm{cm}^{2}$ de parede ruminal e área média das papilas não foi observado efeito de aditivo. Contudo, para superfície da absorção/ $/ \mathrm{cm}^{2}$ de parede ruminal foi observada tendência $(\mathrm{P}=0,07) \mathrm{e}$ valor maior, como também foi observada tendência e maior $(\mathrm{P}=0,10)$ área papilar $(\%$ da superfície de absorção) para o tratamento com adição de MON (Tabela 2). Com a utilização de monensina sódica na dieta de bovinos confinados, ocorre aumento na produção de propionato através da fermentação ruminal, sendo o propionato juntamente com o butirato os maiores estimuladores de crescimento papilar em relação ao acetato (GORKA et al., 2009). Kutas et al. (1983) observaram menor incidência de aglomeração e menor crescimento anormal de papilas em ovinos que receberam monensina na ração e concluíram que o efeito positivo da monensina sobre a morfologia papilar pode estar associado à alteração no perfil de fermentação ruminal, uma vez que os animais tratados com monensina apresentaram concentrações de butirato inferiores aos animais não tratados, sendo o butirato um dos principais causadores de crescimento anormal e aglomeração de papilas além de apresentar efeito queratinizante (COSTA et al., 2008). As papilas aumentam a área de superfície do rúmen, contribuindo profundamente para maior superfície da absorção/ $\mathrm{cm}^{2}$ de parede ruminal e área papilar disponível para absorção de AGCC (COSTA et al., 2008), como observado no presente estudo com a inclusão de MON, apesar das variáveis número de papilas $/ \mathrm{cm}^{2}$ de parede ruminal e área média das papilas não terem sofrido efeito de tratamento. Nesse sentido, o uso de monensina sódica poderia indiretamente controlar a acidose por evitar o acúmulo de AGCC no rúmen.

Foi observado efeito $(\mathrm{P}<0,01)$ de PAP com diminuição do percentual de $\mathrm{AH}$ e a 
Em extensa revisão sobre dietas com elevados teores de concentrado, Wise et al. (1968) observaram que tais dietas foram associadas com aumento da incidência de ruminites, abcessos do fígado, diminuição da ingestão de alimentos e timpanismo. Esses autores sugeriram que o complexo ruminite-abcesso hepático foi o problema mais significativo relacionado com dietas de alta energia, e ainda observaram que a adição de 10 a $15 \%$ de volumoso em dietas de confinamento foi o melhor método disponível para prevenir ruminite. A patologia de abscessos no fígado sugere que ruminites são condições inseparáveis porque permite que os microrganismos entrem na circulação portal e infectem o fígado (VECHIATO et al., 2011).

No estudo conduzido por Jensen et al. (1954), foi observado durante a inspeção de 1.535 bovinos abatidos uma incidência de $41 \%$ de $\mathrm{AH}$ em $55 \%$ de rúmen com lesão, em comparação aos $23 \%$ em $45 \%$ provenientes de rúmen sadio, respectivamente. Os autores concluíram que quando há quadros de $\mathrm{AH}$, estes estão relacionados a quadros prévios de ruminites. Entretanto neste estudo, o IR foi muito baixo como visto anteriormente, mesmo em animais que não receberam os aditivos (controle). Assim sendo, neste estudo, o grau de lesões ruminais não contribuiu de forma importante para a incidência de $\mathrm{AH}$ nos animais.

Com isso, é possível explicar parte de outras possíveis causas do surgimento dos $\mathrm{AH}$ em bovinos, focos que gerem quadros purulentos em demais órgãos, como por exemplo, nos rins, endocárdio e tecido subcutâneo, e que possam emitir êmbolos sépticos que culminem com a geração de AH. Surpreendentemente, um único lóbulo pulmonar parcialmente hepatizado pode aumentar o risco do surgimento de $\mathrm{AH}$ (VECHIATO et al., 2011). A real causa desta predisposição não é conhecida, mas especula-se que em lóbulos parcialmente hepatizados, possa ocorrer com maior frequência necrose tecidual e endotelial possibilitando a emissão de êmbolos sépticos para outros órgãos mais irrigados, como o fígado, originando quadros de $\mathrm{AH}$. Contudo, não foram avaliados neste estudo frequência e grau de hepatização pulmonar. Dessa forma, o uso de anticorpos policlonais foi eficiente na redução de abscessos hepáticos bem como na sua severidade, podendo ser utilizado em dietas de elevada proporção de concentrado para bovinos confinados, porém não foi capaz de melhorar a forma e a estrutura das papilas ruminais, como observado com o uso de monensina sódica.

\section{AGRADECIMENTOS}

Os autores agradecem à Faculdade de Medicina Veterinária e Zootecnia da UNESP/Botucatu, ao Departamento de Melhoramento e Nutrição Animal, a Pós Graduação, a Fundação de Amparo à Pesquisa do Estado de São Paulo, FAPESP (Processo $n^{o}$ 2008/52542-3) e a todos funcionários da UNESP/Botucatu que contribuíram nesse projeto.

\section{REFERÊNCIAS}

BAUER, M.L.; HERALD, D.W.; BRITTON, R.A.; KLOPFENSTEIN, T.J.; YATES D.A. Efficacy of laidlomycin propionate to reduce ruminal acidosis in cattle. Journal of Animal Science, v.73, p.3445-3454, 1995.

BERGHMAN, L.R.; WAGHELA, S.D. Antibodies: an alternative for antibiotics? Journal of Animal Science, v.82, p.660666, 2004.

BERNARDES, E.B.; COELHO, S.G.; CARVALHO, A.V.; OLIVEIRA, H.N.; REIS, R.B.; SATURNINO, H.M.; SILVA, C.A.; COSTA, T.C. Efeito da substituição do feno de Tifton 85 pelo caroço de algodão como fonte de fibra na dieta de bezerros. Arquivo Brasileiro de Medicina Veterinária e Zootecnia, v.59, n.4, p.955964, 2007. 
BIGHAM, M.L.; MCMANUS, W.R. Whole wheat grain feeding of lambs. V. effects of roughage and wheat grain mixtures. Australian Journal of Agricultural Research, v.26, p.10531062,1975 .

BLANCH, M.; CALSAMIGLIA, S.; DILORENZO, N.; DICOSTANZO, A.; MUETZEL, S.;WALLACE, R.J.

Physiological changes in rumen fermentation during acidosis induction and its control using a multivalent polyclonal antibody preparation in heifers. Journal of Animal Science, v.87, n.5, p.1722-1730, 2009.

BRINK, D.R.; LOWRY, S.R.; STOCK, R.A.; PARROT, J.C. Severity of liver abscesses and efficiency of feed utilization of feedlot cattle. Journal of Animal Science, v.68, n.5, p.1201-1207, 1990.

COSTA, S.F.; PEREIRA, M.N.; MELO, L.Q.; RESENDE JÚNIOR, J.C.; CHAVES, M.L. Alterações morfológicas induzidas por butirato, propionato e lactato sobre a mucosa ruminal e a epiderme de bezerros: I Aspectos histológicos. Arquivo Brasileiro de Medicina Veterinária e Zootecnia [online], v.60, n.1, p.1-9, 2008.

DILORENZO, N.; DAHLEN, C.R.; DIEZGONZALEZ F.; LAMB G.C.; LARSON, J.E.; DICOSTANZO,A.Effects of feeding polyclonal antibody preparations on rumen fermentation patterns, performance, and carcass characteristics of feedlot steers. Journal of Animal Science, v.86, n.11, p.3023-3032, 2008.

DILORENZO, N.; DIEZ-GONZALEZ, F.; DICOSTANZO, A. Effects of feeding polyclonal antibody preparations on ruminal bacterial populations and ruminal $\mathrm{pH}$ of steers fed high-grain diets. Journal of Animal Science, v.84, n.8, p.21782185, 2006.
GORKA, P.; KOWALSKI, Z.M.; PIETRZAK, P.; KOTUNIA, A.; KILJANCZYK, R.; FLAGA, J.; HOLST, J.J.; GUILLOTEAU, P.; ZABIELSKI, R. Effect of sodium butyrate supplementation in milk replacer and starter diet on rumen development in calves. Journal of Physiology and Pharmacology, v.60, n.3, p.47-53, 2009.

JENSEN, R.; CONNELL, W.E.; DEEM, A.W. The rumenits-liver abscess complex in beef cattle. American Journal of Veterinary Research, v.15, n.56, p.202-216, 1954.

KRAUSE, K.M.; OETZEL, G.R. Understanding and preventing subacuteruminal acidosis in dairy herds: review. Animal Feed Science and Technology, v.126, p.215-236, 2006.

KUTAS, F.; GÁLFI, P.; NEOGRÁDY, $S$. Effect of monensin on development of ruminalparakeratosis in fattening lambs.

Zentralbl Veterinarmed, v.30, n.7, p.506-510, 1983.

MARIANI, T.M. Suplementação de anticorpos policlonais ou monensina sódica sobre o comportamento ingestivo e desempenho de bovinos brangus e nelore confinados. 2010. 90f. Dissertação (Mestrado) - Universidade de São Paulo, São Paulo.

MARINO, C.T.; OTERO, W.G.; RODRIGUES, P.H.M.; DICOSTANZO, A.; MILLEN, D. D.; PACHECO, R.L.D.; DILORENZO, N.; MARTINS, C.L.; ARRIGONI, M.D.B. Effects of adding polyclonal antibody preparations on ruminal fermentation patterns and digestibility of cows fed different energy sources. Journal of Animal Science, v.89, n.10, p.3228-3235, 2011.

NAGARAJA, T.G.; LECHTENBERG, K.F. Liver abscess in feedlot cattle.

Veterinary Clinics Food Animal, v.23, n.2, p.351-369, 2007a. 
NAGARAJA, T.G.; TITGEMEYER, E.C.

Ruminal acidosis in beef cattle: the current microbiological and nutritional outlook.

Journal of Dairy Science, v.90, p.17-38.

2007b.

NEWBOLD, C.J. New products for rumen manipulation. British Journal of

Nutrition, v.98, n.1, p.15-16, 2007.

PACHECO, D.D.; MILLEN, D.D.;

DILORENZO, N.; MARTINS, C.L.;

MARINO, C.T.; FOSSA, M.V.; BEIER,

S.L.; DICOSTANZO, A.; RODRIGUES, P.H.M.; ARRIGONI, M.D.B. Effects of feeding a multivalent polyclonal antibody preparation on feedlot performance, carcass characteristics, rumenitis, and blood gas profile in Bosindicus biotype yearling bulls. Journal of Animal

Science, v.90, n.6, p.1898-1909, 2012.

RESENDE JÚNIOR, J.C.; ALONSO, L.S.; PEREIRA, M.N.; ROCA, M.G.M.;

DUBOC, M.V.; OLIVEIRA, E.C.; MELO, L.Q. Effect of the feeding pattern on rumen wall morphology of cows and sheep.Brazilian Journal of Veterinary

Research and Animal Science, v.43, n.4, p.526-536, 2006.

STATISTICAL ANALYSIS SYSTEMS. SAS User's Guide: Statistics. Release 9.1. Cary, NC: SAS Inst. Inc., 2003.

VECHIATO, T.A.F; MASCHIO, W.; BOM, L.C.; LOPES, P.D.; ORTOLANI, E.L. Retrospective study of liver abscesses in beef cattle slaughtered in a Brazilian abattoir. Brazilian Journal of Veterinary Research and Animal Science, v.48, n.5, p.384-391, 2011.

WISE, M.B.; HARVEY, R.W.; HASKINS, B.R.; BARRICK E.R. Finishing beef cattle on all-concentrate rations. Journal of Animal Science, v.27, p.1449-1461, 1968.

Data de recebimento: 21/10/2014

Data de aprovação: 11/03/2015 